Article

\title{
An Anabolic Signaling Response of Rat Soleus Muscle to Eccentric Contractions Following Hindlimb Unloading: A Potential Role of Stretch-Activated Ion Channels
}

\author{
Sergey Tyganov, Timur Mirzoev *(D) and Boris Shenkman \\ Myology Laboratory, Institute of Biomedical Problems RAS, 123007, 76A Khoroshevskoe shosse, \\ 123007 Moscow, Russia; sentackle@yandex.ru (S.T.); bshenkman@mail.ru (B.S.) \\ * Correspondence: tmirzoev@yandex.ru; Tel.: +7-499-195-63-10; Fax: +7-499-195-22-53
}

Received: 8 February 2019; Accepted: 4 March 2019; Published: 7 March 2019

check for updates

\begin{abstract}
Mechanisms that convert a mechanical signal into a biochemical response in an atrophied skeletal muscle remain poorly understood. The aims of the study were to evaluate a temporal response of anabolic signaling and protein synthesis (PS) to eccentric contractions (EC) in rat soleus during hindlimb unloading (HU); and to assess a possible role of stretch-activated ion channels (SAC) in the propagation of a mechanical signal to mTORC1 following HU. Following HU, an isolated soleus was subjected to EC. Upon completion of EC, muscles were collected for western blot analyses to determine the content/phosphorylation of the key anabolic markers. We found that a degree of EC-induced p70S6K phosphorylation and the rate of PS in the soleus of 3- and 7-day unloaded rats was significantly less than that in control. A decrease in EC-induced phosphorylation of p70S6K, RPS6 and PS in the 7-day unloaded soleus treated with SAC inhibitor did not differ from that of the 7-day unloaded soleus without SAC blockade. The results of the study suggest that (i) HU results in a blunted anabolic response to a bout of EC, (ii) attenuation of mTORC1-signaling and PS in response to EC in unloaded soleus may be associated with inactivation of SAC.
\end{abstract}

Keywords: soleus muscle; hindlimb unloading; eccentric contractions; protein synthesis; anabolic signaling; stretch-activated channels

\section{Introduction}

In both space physiology and rehabilitation medicine, it is critical to develop new effective exercise and pharmacological countermeasures in order to attenuate/prevent disuse-induced skeletal muscle atrophy as well as to enhance skeletal muscle recovery (regrowth) following a long period of inactivity. It is widely recognized that mechanical tension plays a key role in the regulation of skeletal muscle mass. Chronic mechanical loading results in an increase in muscle mass, while chronic mechanical unloading leads to muscle loss [1]. In order to understand how mechanical stimuli regulate muscle mass, it is important to comprehend how skeletal muscles sense mechanical signals and convert them into biochemical events (mechanotransduction) regulating the rate of protein synthesis (PS). It is now well-established that mammalian/mechanistic target of rapamycin complex 1 (mTORC1) plays a key role in the regulation of skeletal muscle PS and muscle mass in response to mechanical stimuli [2-5]. Phosphorylation of 70kDa ribosomal protein S6 kinase (p70S6K) on the Thr389 residue is typically used as a read-out of mTORC1-signaling. In addition to the mTORC1/p70S6K signaling, there are mTORC1-independent signaling pathways that are able to activate PS, in particular, glycogen synthase kinase-3 $\beta$ (GSK-3 $\beta$ )/initiation factor 2B (eIF2B) and extracellular signal-regulated kinase (ERK)/90kDa ribosomal protein S6 kinase (p90RSK) pathways [6,7]. It is important to note the role 
of stretch-activated ion channels (SAC) as possible mechanosensors of skeletal muscle fibers. These channels were first described in cultured skeletal muscle cells as mechanosensitive ion channels, which increase their open probability in response to mechanical stress [8]. It has been suggested that SAC are critical for a number of cellular processes, including electrolyte homeostasis and signal transduction $[9,10]$. SAC described in skeletal muscle appear to be permeable to $\mathrm{Ca}^{2+}$ and $\mathrm{Na}^{+}$ions, and this action can be inhibited by gadolinium ions $\left(\mathrm{Gd}^{3+}\right)[10]$. However, to date, molecular mechanisms involved in sensing and converting an external mechanical signal into an anabolic response in an atonied/atrophied mammalian skeletal muscle remain undefined. We hypothesized that an eccentric contractions (EC)-induced anabolic response in rat soleus muscle following hindlimb unloading would be attenuated. Furthermore, this blunted anabolic response could be associated with impaired function of SAC. Therefore, the aims of the present study were (i) to evaluate a temporal response of anabolic signaling and protein synthesis (PS) to a bout of EC in the rat soleus at different time points of mechanical unloading and (ii) to assess a possible role of SAC in the propagation of a mechanical signal to mTORC1 in the soleus muscle following hindlimb unloading (HU).

\section{Results}

\subsection{Experiment 1}

2.1.1. Body Weight, Soleus Weight to Body Weight Ratio and Mean Maximal Eccentric Tetanic Force $\left(\mathrm{P}_{0}\right)$ Normalized to Muscle Cross-Sectional Area

There was no significant difference between the groups in body weight (Table 1). Soleus weight to body weight ratio significantly decreased by $16 \%(p<0.05)$ after 7 -day HS compared with the control animals. There was no significant difference between any groups in normalized $\mathrm{P}_{0}$, absolute tetanic tension was decreased after 7-day HS (Table 1).

Table 1. Changes in rat's body weight, soleus weight-to-body weight ratio and $P_{0}$, and $P_{0}$ normalized to muscle cross-sectional area following 1-, 3- and 7 days of hindlimb unloading.

\begin{tabular}{ccccc}
\hline Group & Rat Weight, $\mathbf{g}$ & Soleus Weight, mg/Rat Weight, $\mathbf{g}$ & $\mathbf{P}_{\mathbf{0}}, \mathbf{m N}$ & $\begin{array}{c}\mathbf{P}_{\mathbf{0}} / \text { Cross-Sectional } \\
\text { Area, N/cm }\end{array}$ \\
\hline C & $220 \pm 8$ & $0.40 \pm 0.011$ & $802.4 \pm 24.3$ & $19.4 \pm 1.4$ \\
1HS & $214 \pm 3$ & $0.42 \pm 0.013$ & $744.5 \pm 26.1$ & $18.2 \pm 1.1$ \\
3HS & $222 \pm 10$ & $0.372 \pm 0.015$ & $742.5 \pm 21.7$ & $20.2 \pm 1.0$ \\
7HS & $210 \pm 7$ & $0.336 \pm 0.018^{*}$ & $660.8 \pm 24.9 *$ & $20.2 \pm 1.1$ \\
\hline
\end{tabular}

Values are means \pm SEM. Values are means \pm SEM, expressed relative (\%) to the control resting muscle; $n=7 /$ group. C-control rats, 1HS, 3HS and 7HS - hindlimb unloading for 1, 3 and 7 days. The data were analyzed using one-way ANOVA with post hoc Tukey. Rat weight: the main effect of HS $p=0.158784$, soleus weight $/$ rat weight ratio: the main effect of HS $p=0.001586, \mathrm{P}_{0}$ : the main effect of HS $p=0.002901, \mathrm{P}_{\mathrm{o}} / \mathrm{CSA}$ : the main effect of HS $p=0.589732$;

*-significant difference vs. C group, $p<0.05$.

\subsubsection{The Rate of Muscle Protein Synthesis}

The rate of PS in the resting soleus muscles significantly decreased by approximately $40 \%(p<0.05)$ following 3- and 7 days of HS (Figure 1). A bout of EC of the isolated rat soleus resulted in a significant rise in PS vs. the resting muscle in the $\mathrm{C}, 3 \mathrm{HS}$ and $7 \mathrm{HS}$ groups (Figure 1). 

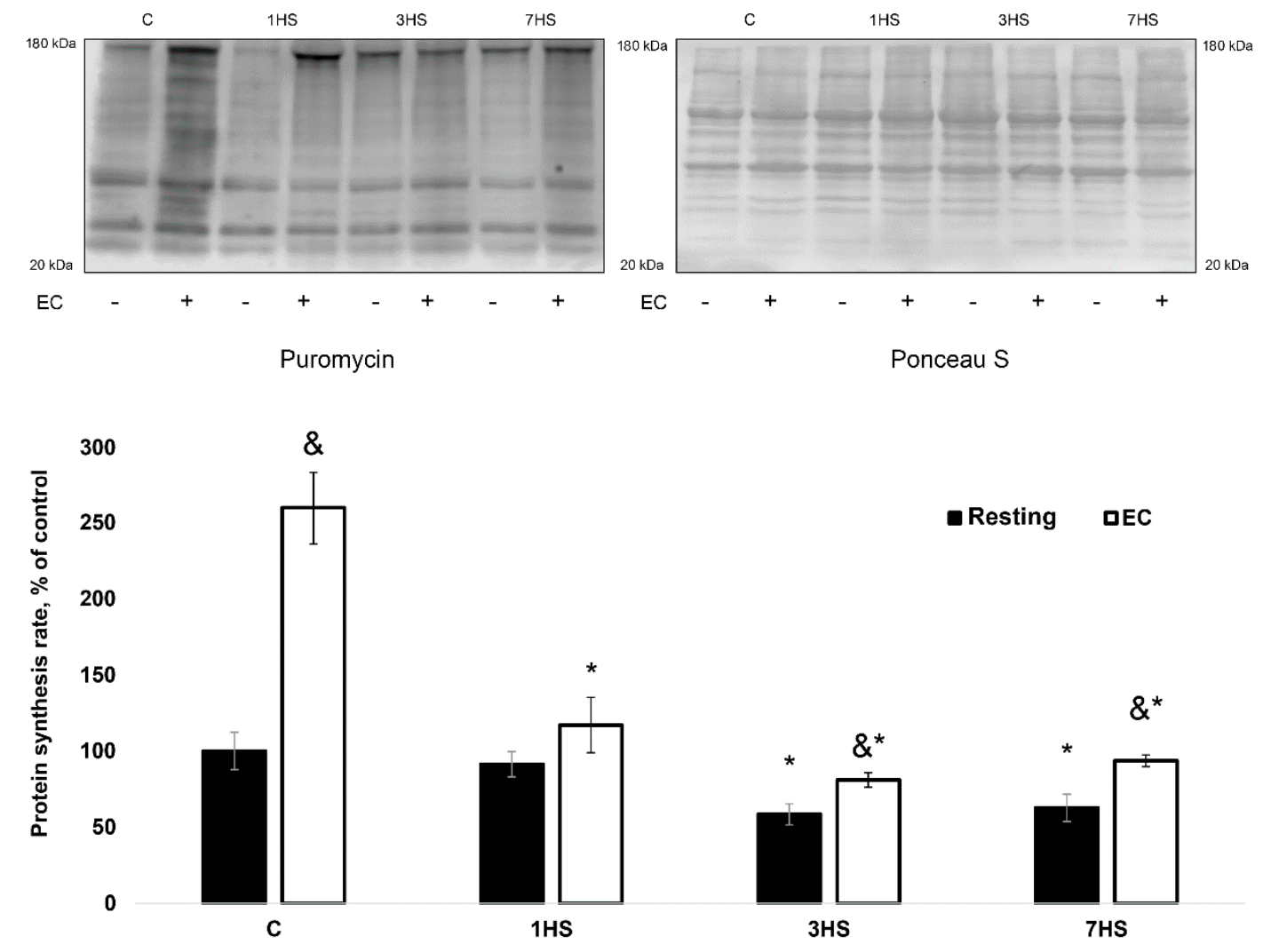

$\&$
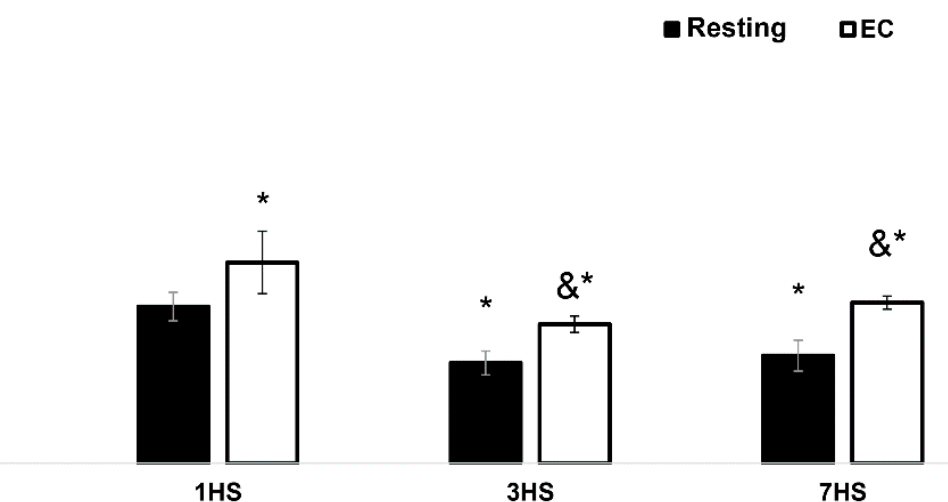

Figure 1. The rate of protein synthesis in the eccentrically-contracted rat soleus muscles following hindlimb unloading (experiment 1 ). Values are means \pm SEM, expressed relative (\%) to the control resting muscle; $n=7$ /group. C-control rats, $1 \mathrm{HS}, 3 \mathrm{HS}$ and $7 \mathrm{HS}$-hindlimb unloading for 1, 3 and 7 days. The data were analyzed using 2-way ANOVA with post hoc Tukey. The main effect of HS $p=2.00459 \mathrm{E}-11$, the main effect of EC $p=2.74866 \mathrm{E}-08$, interaction effect $p=1.08513 \mathrm{E}-06$; * - significant difference vs. $C$ group $(p<0.05)$, \&-significant difference from the resting muscle of the same group $(p<0.05)$. Black bars—resting muscle, white bars-eccentrically-contracted muscle.

However, the level of EC-induced PS increment in the 1HS, 3HS and 7HS groups was $81 \%, 77 \%$ and $64 \%$ lower $(p<0.05)$, respectively, than that in the $C$ group (Figure $3 a)$.

\subsubsection{Phosphorylation of Key Signaling Proteins Involved in the Regulation of Muscle} Protein Synthesis

In the resting muscle, there was a significant $43 \%(p<0.05)$ decrease in p70S6K phosphorylation in the 7HS group compared to the resting control (Figure 2a). p70S6K (Thr389) was significantly phosphorylated in response to EC in all groups, however EC-induced p70S6K phosphorylation increment in the 3HS and 7HS groups was significantly decreased by 104 and $97 \%(p<0.05)$, respectively, vs. the $\mathrm{C}$ group (Figure $3 \mathrm{~b}$ ). 4E-BP1 (Thr37/46) phosphorylation was significantly decreased in all HS groups compared to the control group in resting muscles (Figure 2b). However, 4E-BP1 (Thr37/46) phosphorylation in response to EC was significantly lower in all groups, and the level of this decline did not differ between the groups (Figure 3c). In the resting isolated muscles of 3 HS and 7HS, GSK-3 $\beta$ (Ser9) phosphorylation was 44 and $47 \%(p<0.05)$ less than that in the resting control muscle (Figure 2c). A bout of EC revealed a significant decrease in GSK-3 $\beta$ phosphorylation increment in the isolated soleus muscles taken from hindlimb-unloaded rats as compared to the control rats (Figure 3d). 7-day HS resulted in a significant 42\% $(p<0.05)$ decrease in p90RSK (T359 + S363) phosphorylation vs. the $C$ group (Figure $2 \mathrm{~d}$ ) in resting soleus muscle. EC-induced increase in p90RSK phosphorylation was observed in the $\mathrm{C}$ group as well as in the $1 \mathrm{HS}$ and $7 \mathrm{HS}$ groups, but this increased p90RSK phosphorylation was not statistically different among these groups (Figure 3e). 
(a)
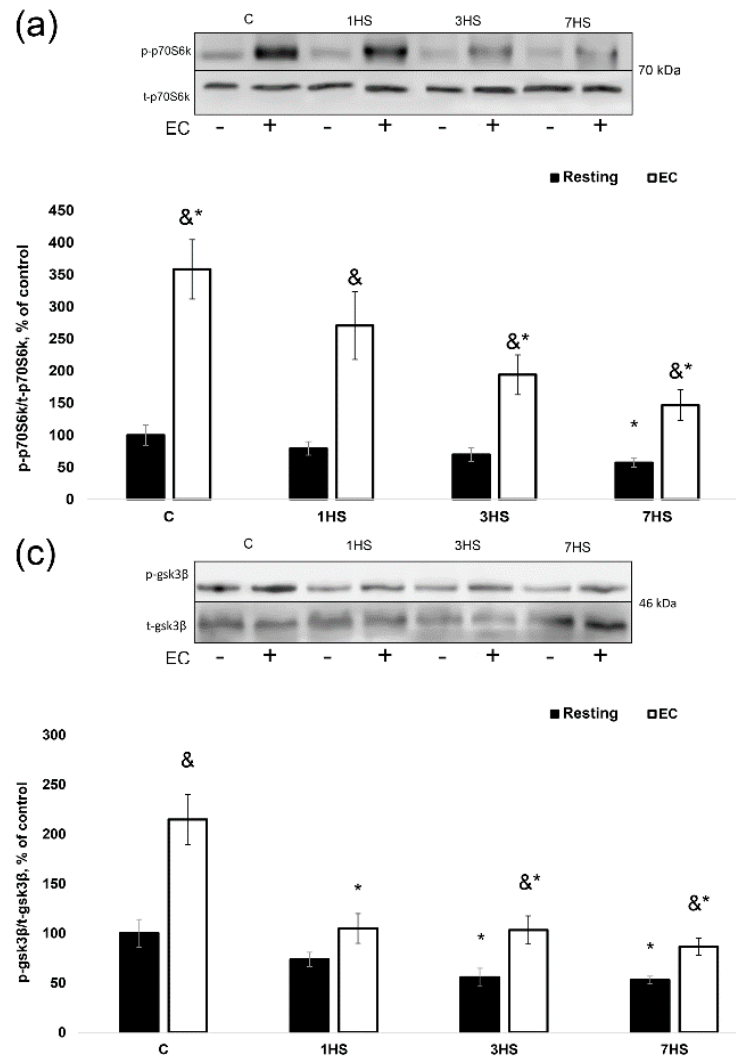

(b)
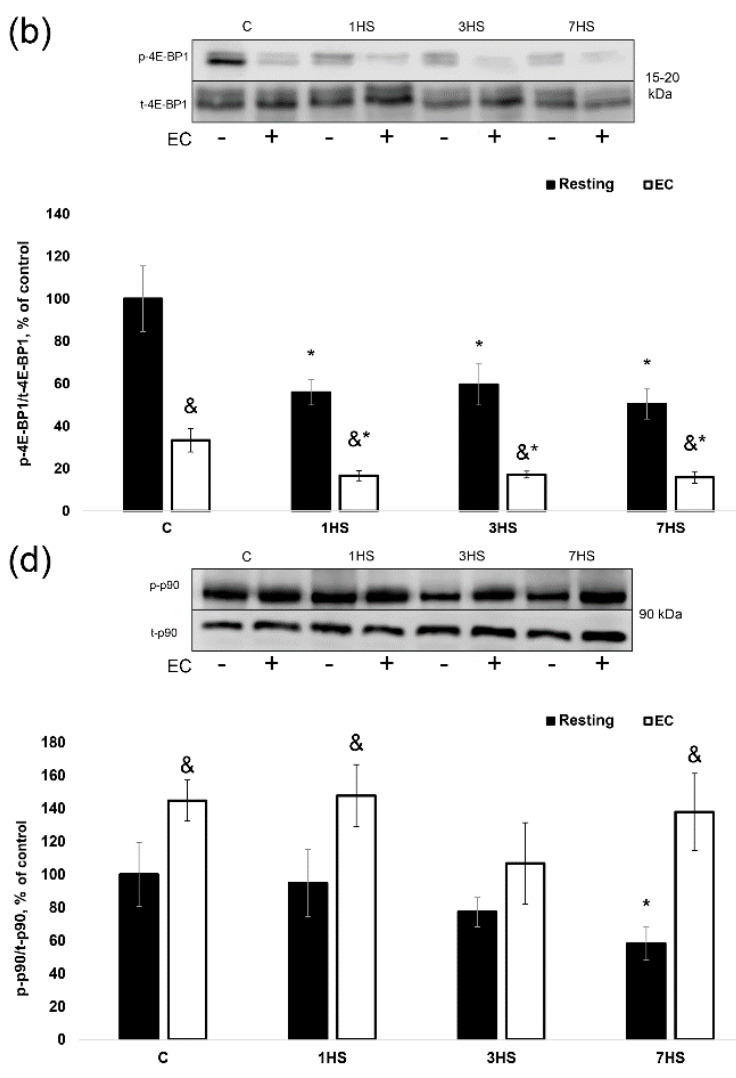

Figure 2. Phosphorylation status of the key anabolic signaling proteins in the eccentrically-contracted rat soleus muscles following hindlimb unloading (experiment 1). (a): p70S6K (Thr389) phosphorylation; (b): 4E-BP1 (Thr37/46) phosphorylation; (c): GSK-3ß (Ser9) phosphorylation; (d): p90RSK (Thr359/Ser363) phosphorylation. Values are means \pm SEM, expressed relative (\%) to the control resting muscle; $n=7$ /group. C-control rats, $1 \mathrm{HS}$, 3HS and 7HS-hindlimb unloading for 1, 3 and 7 days. The data were analyzed using 2-way ANOVA with post hoc Tukey. p70S6K (Thr389) phosphorylation: the main effect of HS $p=9,18811 \mathrm{E}-06$, the main effect of EC $p=1,34515 \mathrm{E}-13$, interaction effect $p=0,003124$; 4E-BP1 (Thr37 /46) phosphorylation: the main effect of HS $p=0,000353$, the main effect of EC $p=2,00982 \mathrm{E}-10$, interaction effect $p=0,021799$; GSK-3 $\beta$ (Ser9) phosphorylation: the main effect of HS $p=1,01182 \mathrm{E}-08$, the main effect of EC $p=5,21828 \mathrm{E}-08$, interaction effect $p=0,005360$; p90RSK (Thr359/Ser363) phosphorylation: the main effect of HS $p=0,125909$, the main effect of EC $p=2,04532 \mathrm{E}-05$, interaction effect $p=0,448363$; *-significant difference vs. C group $(p<0.05)$, $\&$ - significant difference from the resting muscle of the same group $(p<0.05)$. Black bars-resting muscle, white bars-eccentrically-contracted muscle. 
(a)

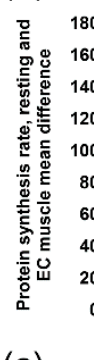

(c) (b)

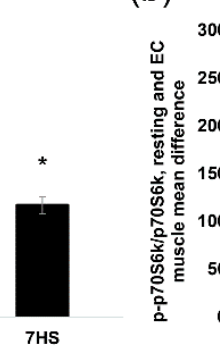

(d)
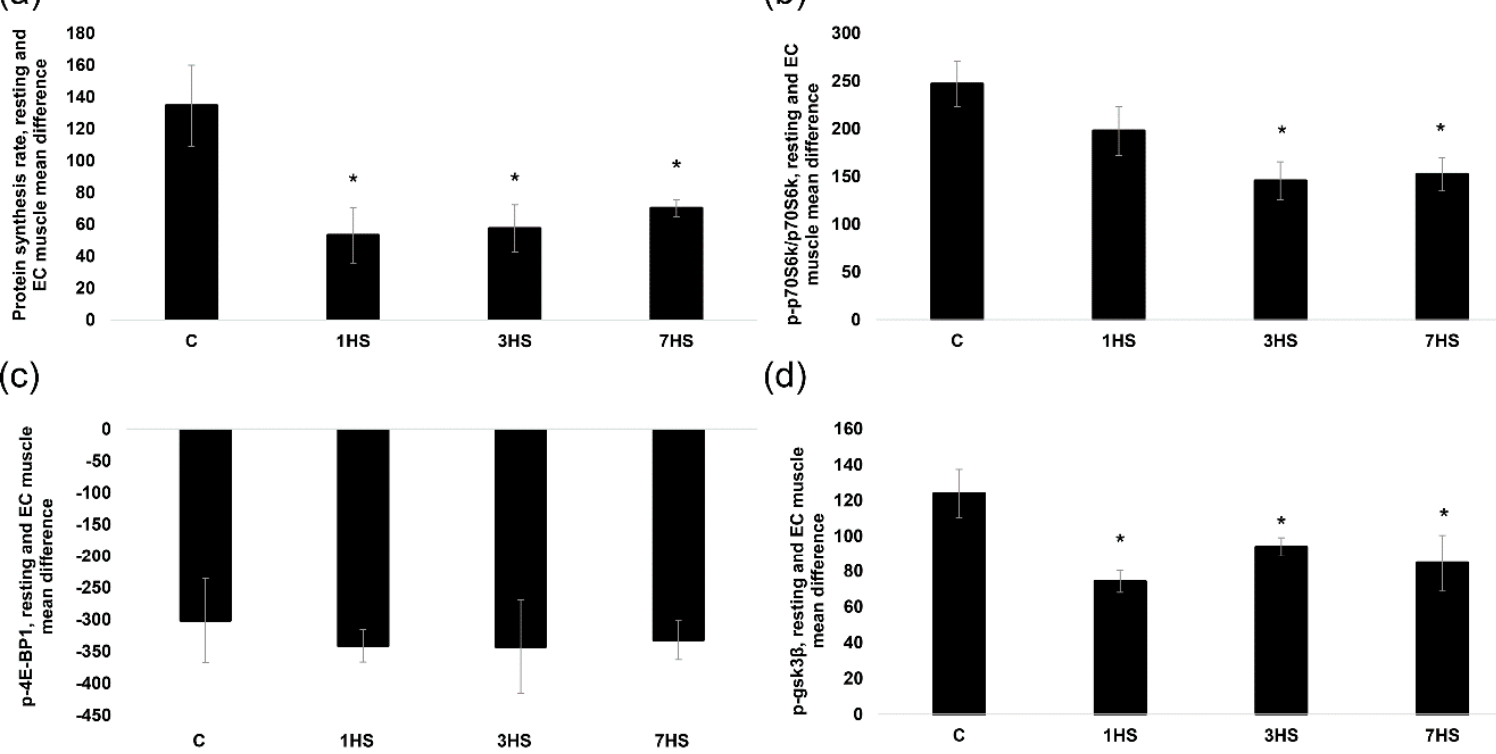

(e)

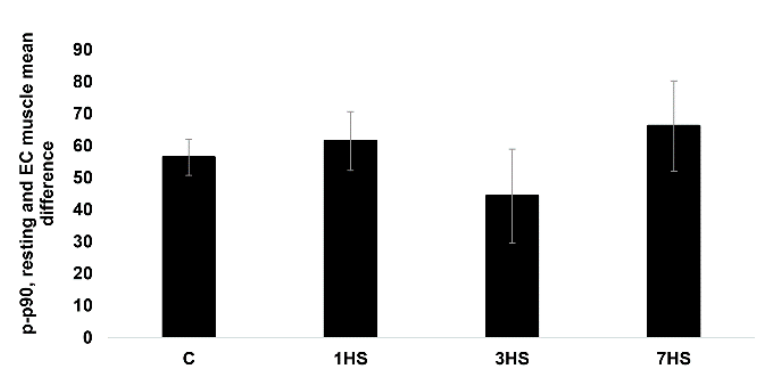

Figure 3. The mean difference in the rate of protein synthesis and phosphorylation of anabolic markers between resting and eccentrically-contracted muscles (experiment 1). (a): The rate of protein synthesis; (b): p70S6K (Thr389) phosphorylation; (c): 4E-BP1 (Thr37/46) phosphorylation; (d): GSK-3ß (Ser9) phosphorylation; (e): p90RSK (Thr359/Ser363) phosphorylation. Values are means \pm SEM; $n=7 /$ group. C-control rats, 1HS, 3HS and 7HS-hindlimb unloading for 1, 3 and 7 days. * - significant difference vs. C group $(p<0.05)$. The data were analyzed using one-way ANOVA with post hoc Tukey. Protein synthesis: the main effect of HS $p=3,87195 \mathrm{E}-06$; p70S6K (Thr389) phosphorylation: the main effect of HS $p=0,007496$; 4E-BP1 (Thr37/46) phosphorylation: the main effect of HS $p=0,114387$; GSK-3 $\beta$ (Ser9) phosphorylation: the main effect of HS $p=3,62852 \mathrm{E}-05$; p90RSK (Thr359/Ser363) phosphorylation: the main effect of HS $p=0,381030 ;{ }^{*}$ - significant difference vs. C group $(p<0.05)$.

\subsection{Experiment 2}

2.2.1. Body Weight, Soleus Weight to Body Weight Ratio and Mean Maximal Eccentric Tetanic Force $\left(\mathrm{P}_{0}\right)$ Normalized to Muscle Cross-Sectional Area

Table 2 shows that there was no difference in body weight across the studied groups. The ratio of soleus weight to body weight significantly decreased after 7-day HS as compared to weight-bearing control rats. There was no significant difference between any groups in normalized $\mathrm{P}_{0}$ (Table 2), however absolute tetanic tension was decreased after 7-day HS (Table 2). 
Table 2. Changes in rat's body weight, soleus weight-to-body weight ratio and $\mathrm{P}_{0}$, and $\mathrm{P}_{0}$ normalized to muscle cross-sectional area following 7 days of hindlimb unloading (experiment 2).

\begin{tabular}{ccccc}
\hline Group & Rat Weight, $\mathbf{g}$ & Soleus Weight, $\mathbf{~ m g} /$ Rat Weight, $\mathbf{g}$ & $\mathbf{P}_{\mathbf{0}}, \mathbf{m N}$ & $\mathbf{P}_{\mathbf{0}} /$ Cross-Sectional Area, $\mathbf{~} / \mathbf{c m}^{\mathbf{2}}$ \\
\hline C & $225 \pm 16$ & $0.43 \pm 0.03$ & $940.2 \pm 33.3$ & $23.5 \pm 1.7$ \\
C + Gd & $220 \pm 10$ & $0.44 \pm 0.04$ & $911.4 \pm 15.7$ & $19.4 \pm 1.2$ \\
HS & $226 \pm 8$ & $0.31 \pm 0.03^{*}$ & $715.1 \pm 23.9^{*}$ & $23.6 \pm 1.1$ \\
HS + Gd & $225 \pm 7$ & $0.35 \pm 0.03^{*}$ & $740.6 \pm 15.2^{*}$ & $21.3 \pm 2.0$ \\
\hline
\end{tabular}

Values are means \pm SEM, $n=7$ /group. C-control animals, $\mathrm{C}+\mathrm{Gd}$-control animals with $\mathrm{GdCl}_{3}$ treatment of the isolated soleus, HS-animals subjected to 7-day hindlimb unloading, HS + Gd-hindlimb-unloaded animals with $\mathrm{GdCl}_{3}$ treatment of the isolated soleus. The data were analyzed using 2-way ANOVA with post hoc Tukey. Rat weight: the main effect of HS $p=0,278046$, the main effect of $\operatorname{Gd} p=0,834042$; interaction effect $p=0,345367$; soleus weight/rat weight ratio: the main effect of $\operatorname{HS} p=3,31084 \mathrm{E}-10$, the main effect of $\mathrm{Gd} p=0,059001$; interaction effect $p=0,020047 ; \mathrm{P}_{\mathrm{o}}$ : the main effect of HS $p=1,76513 \mathrm{E}-4$, the main effect of Gd $p=0,234589$; interaction effect $p=0,009768 ; \mathrm{P}_{\mathrm{o}} / \mathrm{CSA}$ : the main effect of HS $p=0,546122$, the main effect of $\mathrm{Gd} p=0,216795$; interaction effect $p=0,619122 ; *$ * significant difference vs. C group; $p<0.05$.

\subsubsection{The Rate of Muscle Protein Synthesis}

As expected, the rate of PS in the resting muscles of the unloaded rats significantly declined $(-40 \%, p<0.05)$ compared to the control values (Figure 4). EC-induced increase in PS was $170 \%$ less $(p<0.05)$ in the $\mathrm{C}+\mathrm{Gd}$ group vs. the $\mathrm{C}$ group. More importantly, EC-induced increase in PS was significantly less in the HS and HS + Gd groups vs. the $C$ group (Figure 6a). There was no statistically significant difference between the HS and HS + Gd groups in terms of EC-induced increase in muscle PS (Figure 6a).
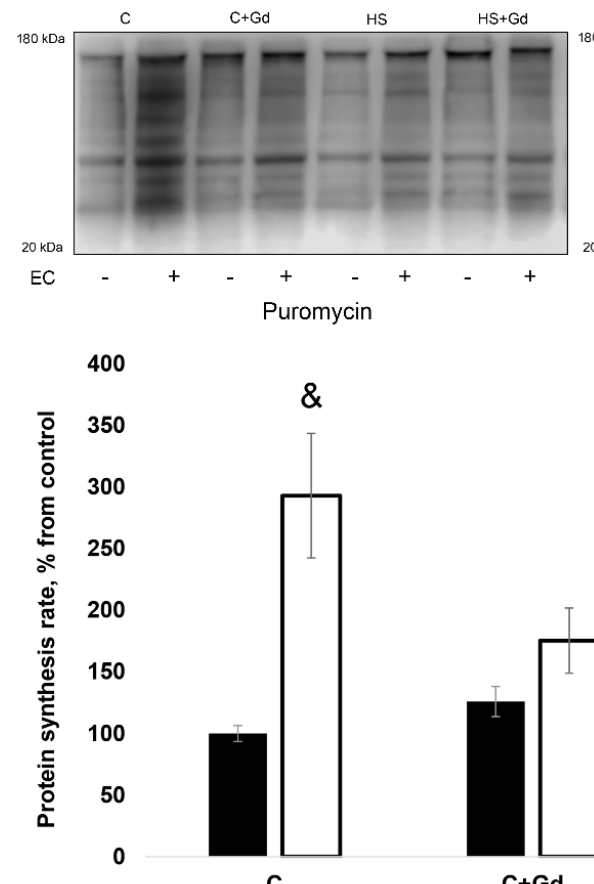

C
$\&$

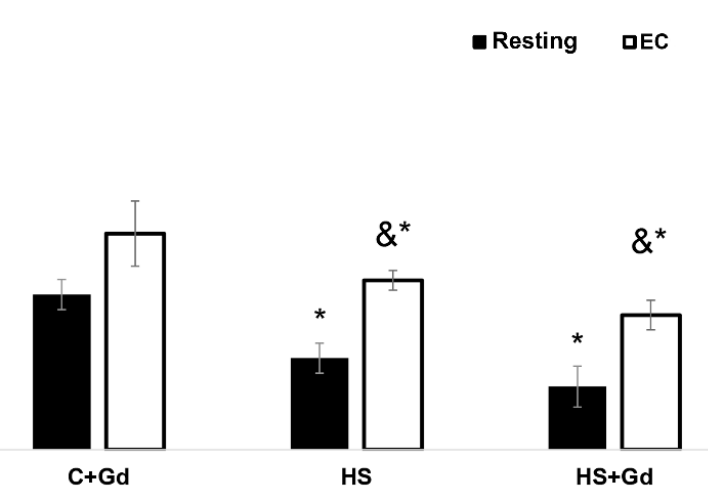

Figure 4. The effect of SAC blockade on the rate of protein synthesis in the eccentrically-contracted rat soleus muscles following 7-day hindlimb unloading (experiment 2). Values are means $\pm \mathrm{SEM}$, expressed relative (\%) to the control resting muscle; $n=7$ /group. C-control animals, $\mathrm{C}+\mathrm{Gd}-$ control animals with $\mathrm{GdCl}_{3}$ treatment of the isolated soleus, HS-animals subjected to 7-day hindlimb unloading, $\mathrm{HS}+\mathrm{Gd}$-hindlimb-unloaded animals with $\mathrm{GdCl}_{3}$ treatment of the isolated soleus. The data were analyzed using 3-way ANOVA with post hoc Tukey. The main effect of HS $p=1,51656 \mathrm{E}-06$, the main effect of EC $\mathrm{p}=3,23095 \mathrm{E}-08$, the main effect of Gd treatment $p=0,000187$; interaction effect $p=0,000731$; * - significant difference vs. C group $(p<0.05)$, \&-significant difference from the resting muscle of the same group $(p<0.05)$. Black bars—resting muscle, white bars—eccentrically-contracted muscle. 
2.2.3. Phosphorylation of Key Signaling Proteins Involved in the Regulation of Muscle Protein Synthesis

In the isolated resting muscles, p70S6K (Thr389) phosphorylation was significantly decreased in the unloaded groups (HS and HS + Gd) vs. the C group (Figure 5a). In the EC muscles, the level of p70S6K (Thr389) phosphorylation increment was significantly down-regulated in C + Gd (-183\%), HS $(-85 \%)$ and HS+Gd (-79\%) groups in comparison to the control values (Figure $6 \mathrm{~b})$. Similar changes in phosphorylation were observed for RPS6, a known p70S6K substrate. In the resting muscles, RPS6 phosphorylation was significantly declined in the HS and HS + Gd groups as compared to the C group (Figure 5b). The level of RPS6 (Ser 240/244) phosphorylation after a bout of EC was significantly diminished in C+Gd $(-94 \%)$, HS $(-102 \%)$ and HS $+\mathrm{Gd}(-82 \%)$ groups compared to the C group (Figure 6c). As for GSK-3 $\beta$, a marker of mTORC1-independent anabolic pathway, we observed the same pattern of its Ser 9 phosphorylation as seen for p70S6K and RPS6 in resting and EC soleus muscles (Figures $5 \mathrm{c}$ and $6 \mathrm{~d}$ ).

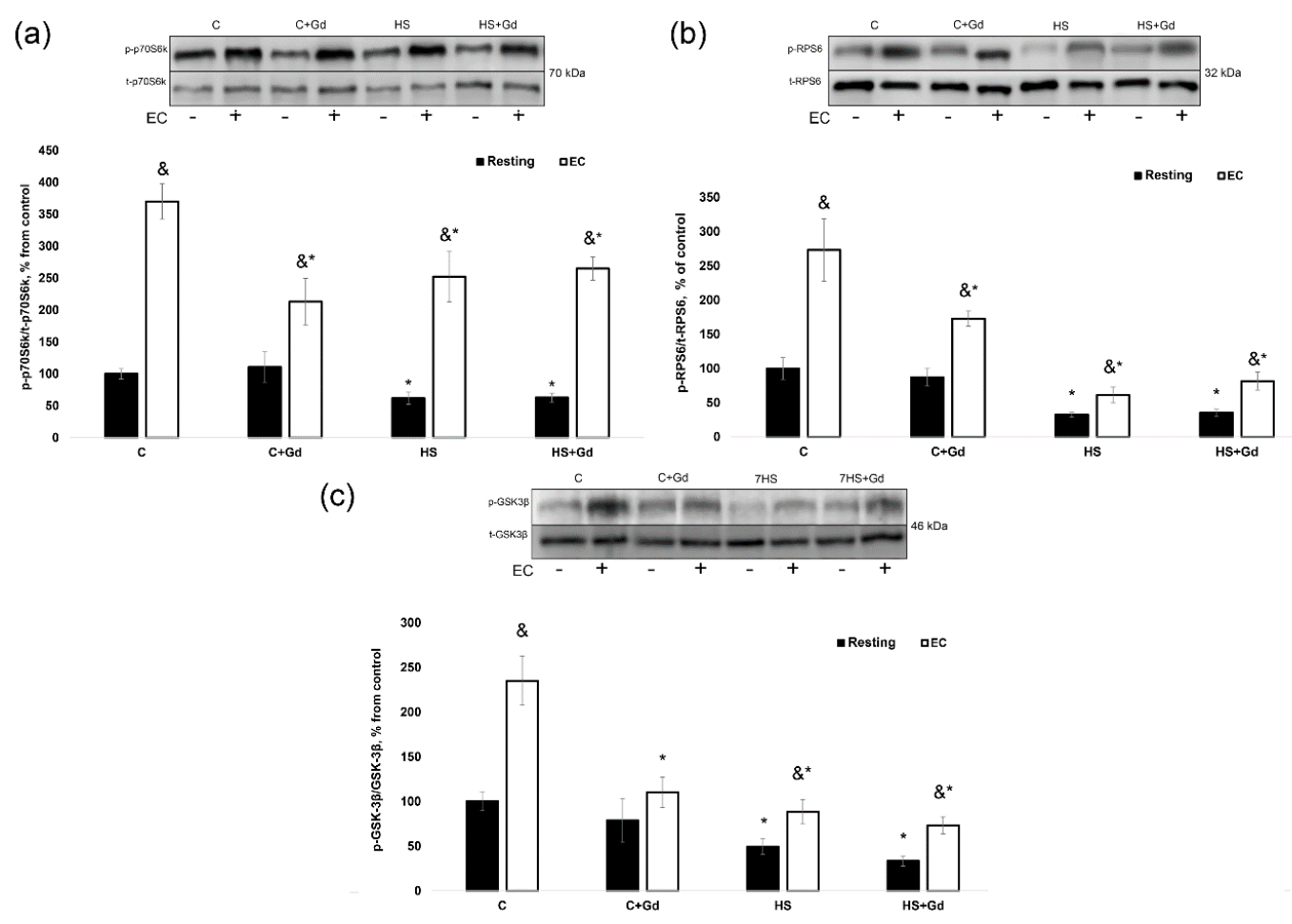

Figure 5. The effect of SAC blockade on the key markers of mTORC1-signaling and GSK-3 $\beta$ in the eccentrically-contracted rat soleus muscles following 7-day hindlimb unloading (experiment 2). (a): p70S6K (Thr 389) phosphorylation; (b): RPS6 (Ser 240/244) phosphorylation; (c): GSK-3ß (Ser 9) phosphorylation. Values are means \pm SEM, expressed relative (\%) to the control resting muscle; $n=7$ /group. C-control animals, $\mathrm{C}+\mathrm{Gd}-$ control animals with $\mathrm{GdCl}_{3}$ treatment of the isolated soleus, HS-animals subjected to 7-day hindlimb unloading, HS+Gd-hindlimb-unloaded animals with $\mathrm{GdCl}_{3}$ treatment of the isolated soleus. The data were analyzed using 3-way ANOVA with post hoc Tukey. p70S6K (Thr389) phosphorylation: the main effect of HS $p=0,001497$, the main effect of EC $p=1,17298 \mathrm{E}-14$, the main effect of Gd treatment $p=0,003678$; interaction effect $p=0,001605$; RPS6 (Ser 240/244) phosphorylation: the main effect of HS $p=2,40305 \mathrm{E}-11$, the main effect of EC $p=4,53626 \mathrm{E}-09$, the main effect of Gd treatment $p=0,000579$; interaction effect $\mathrm{p}=0,000302$; GSK-3 $\beta$ (Ser9) phosphorylation: the main effect of HS $p=1,26748 \mathrm{E}-06$, the main effect of EC $p=4,4602 \mathrm{E}-07$, the main effect of Gd treatment $p=0,003129$; interaction effect $p=0,010773$; *-significant difference vs. C group $(p<0.05), \&$ significant difference from the resting muscle of the same group $(p<0.05)$. Black bars-resting muscle, white bars-eccentrically-contracted muscle. 
(a)

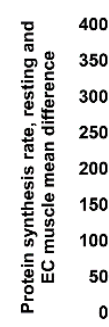

(c)

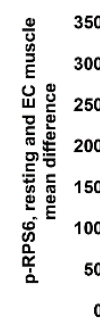

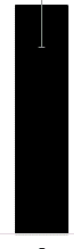

c
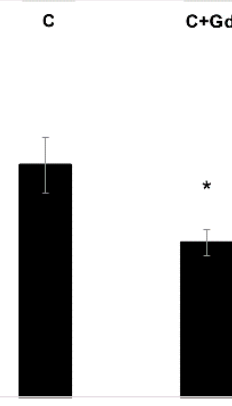

c

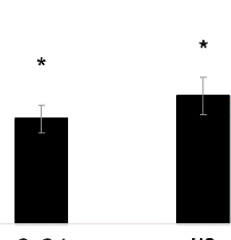

HS

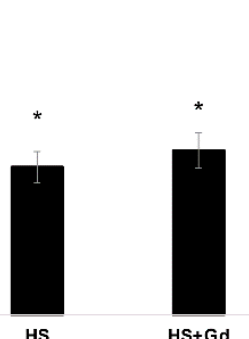

(b)

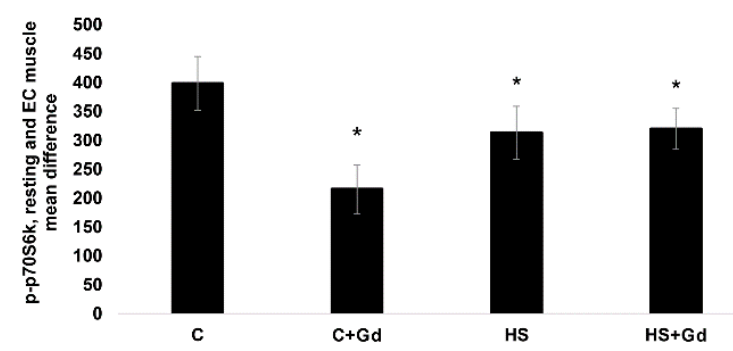

(d)

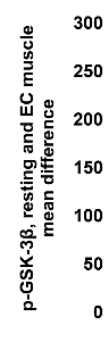

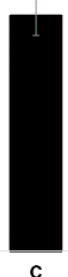

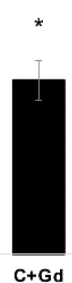

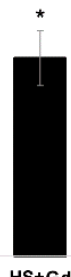

Figure 6. The mean difference in the rate of protein synthesis and phosphorylation of anabolic markers between resting and eccentrically-contracted muscles (experiment 2). (a): The rate of protein synthesis; (b): p70S6K (Thr389) phosphorylation; (c): RPS6 (Ser 240/244) phosphorylation; (d): GSK-3ß (Ser9) phosphorylation. Values are means $\pm \mathrm{SEM} ; n=7$ /group. $\mathrm{C} —$ control animals, $\mathrm{C}+\mathrm{Gd}-$ control animals with $\mathrm{GdCl}_{3}$ treatment of the isolated soleus, HS-animals subjected to 7-day hindlimb unloading, $\mathrm{HS}+\mathrm{Gd}$ - hindlimb-unloaded animals with $\mathrm{GdCl}_{3}$ treatment of the isolated soleus. The data were analyzed using 2-way ANOVA with post hoc Tukey. Protein synthesis: the main effect of HS $p=0,026604$, the main effect of EC $p=0,008589$, interaction effect $p=0,026372$; p70S6K (Thr389) phosphorylation: the main effect of HS $p=0,001192$, the main effect of EC $p=0,023999$, interaction effect $p=0,011959$; RPS6 (Ser 240/244) phosphorylation: the main effect of HS $\mathrm{p}=0,002087$, the main effect of EC $p=0,020173$, interaction effect $p=0,062066$; GSK-3 $\beta$ (Ser9) phosphorylation: the main effect of HS $p=0,006279$, the main effect of EC $p=0,001944$, interaction effect $p=0,002417$; ${ }^{*}$-significant difference vs. C group $(p<0.05)$.

\section{Discussion}

To our knowledge, here we demonstrate for the first time a significant decrease in EC-induced PS rate as well as mTORC1-signaling in the isolated rat soleus muscle following 3 and 7 days of mechanical unloading. Moreover, our data suggest that attenuated anabolic response of the unloaded rat soleus could be associated, at least partially, with functional inactivation of SAC. The key finding of this study is that in the unloaded soleus muscle, both p70S6K (Thr389) phosphorylation and the rate of PS had a similar attenuated response to a bout of EC. This indicates that the first 1-3 days of unloading are enough to induce impaired transmission of a mechanical signal to PS in rat postural muscle. It is interesting to note, that, unlike other anabolic markers, 4E-BP1 phosphorylation in response to a bout of EC was reduced in all groups as compared to corresponding resting muscles. These data are consistent with Ato et al. (2016), who showed that immediately after EC the phosphorylation level of 4E-BP1 was significantly lower than that in the resting control muscle, while p70S6K (Thr389) phosphorylation was significantly higher compared to the resting control [11]. Apparently, $30 \mathrm{~min}$ period post EC was not enough to cause hyperphosphorylation of 4E-BP1. Mechanical unloading did not affect EC-induced p90RSK in the rat soleus muscle, indicating that ERK1/2 signaling pathway was not involved in the blunted anabolic response. As for GSK-3 $\beta$, it can be suggested that the temporal pattern of its phosphorylation could be associated with a change in glycogen content that is known to increase in skeletal muscle fibers under unloading conditions [12]. However, the exact mechanism of GSK-3 $\beta$ activity regulation in response to EC during unloading remains unknown. 
The obtained data concerning PS rate and phosphorylation of anabolic markers (p7056K, p90RSK, GSK-3 $\beta$ ) in the resting rat soleus generally agree with previously published reports of our laboratory $[13,14]$ as well as other researchers [15-18].

A decrease in EC-induced anabolic response of the unloaded rat soleus muscle could be due to the impairment of both mechanosensory structures of the muscle fiber (such as SAC) and signaling molecules involved in mechanotransduction (such as focal adhesion kinase). In addition, an important role can be provided by the cytoskeleton in the transmission of a mechanical signal from the surface of the muscle fiber to anabolic regulatory proteins [19]. For example, HU-induced decrease in desmin content in rat soleus muscle $[20,21]$, could interfere with a propagation of a mechanical signal to muscle PS. There is evidence that mechano-dependent activation of mTORC1 is directly mediated by phosphatidic acid, which is synthesized with the help of $\zeta$-isoform of diacylglycerol kinase (DGK- $\zeta$ ) [22].

Given that SAC are important skeletal muscle fiber mechanosensors [9], we further sought to assess a possible role of SAC in the propagation of a mechanical signal to mTORC1 and PS in the soleus muscle following 7-day hindlimb unloading. It has been previously been shown that SAC blockade with gadolinium or streptomycin can lead to a decrease in muscle fibers membrane depolarization $[23,24]$ as well as a decrease in the degree of rat tibialis anterior hypertrophy following repeated eccentric contractions [23]. Furthermore, SAC appear to be necessary for full EC-induced activation of AKT and p70S6K in rat tibialis anterior muscle [25]. In the current study, a significant decrease in the phosphorylation level of the key mTORC1 targets and GSK-3 $\beta$ in the isolated rat soleus muscle in response to EC was observed both in the HS group and the HS+Gd group. Since the inhibition of SAC with $\mathrm{Gd}^{3+}$ did not lead to further decline in the EC-induced phosphorylation of the key anabolic markers (GSK-3 $\beta$, p70S6K, RPS6) compared to the HS group, our data indicate that 7-day hindlimb unloading alone can induce SAC downregulation with subsequent attenuation of mTORC1-signaling and PS.

Previously it has been shown that a bout of EC results in a significant elevation of intracellular $\mathrm{Ca}^{2+}$ in rat skeletal muscle and that SAC may play a permissive role in this process [26]. Stretch-activated $\mathrm{Ca}^{2+}$ ion channels contribute to the $\mathrm{Ca}^{2+}$ influx into myofibers which activates calmodulin [27]. Calmodulin interacts with the human vacuolar protein sorting-34 (hVPS34) and activates mTORC1 in the presence of essential amino acids [28]. Zanou et al. (2012) identified a $\mathrm{Ca}^{2+}$-dependent activation of the PI3K/Akt/mTOR/p70S6K pathway during myoblast differentiation and skeletal muscle regeneration [29]. Although the exact mechanisms for how calcium ions may affect anabolic signaling pathways in skeletal muscle are still undefined, there is evidence that an overload-induced transient receptor potential cation channel subfamily V member 1 (TRPV1)-mediated increase in intracellular $\mathrm{Ca}^{2+}$ concentration can lead to the activation of mTORC1 [30]. Importantly, this load-induced elevation in $\mathrm{Ca}^{2+}$ concentration was not completely prevented in Trpv1-null myotubes, suggesting that other ion channels (such as SAC) might also be involved in load-induced increase in $\mathrm{Ca}^{2+}$ levels and subsequent mTORC1 activation. It is also worth noting that in embryonic kidney cells it has been shown that initial priming step for p70S6K activation is calcium-dependent, and failure of this priming step to occur results in a global reduction of p70S6K phosphorylation [31]. Therefore, it is possible that unloading-induced attenuation of SAC function could contribute to the blunted anabolic response of the isolated rat soleus to mechanical stimuli (eccentric contractions). However, elucidation of the precise molecular mechanism(s) underlying transmission of a mechanical signal from SAC to mTORC1 and muscle protein synthesis awaits further investigation.

\section{Materials and Methods}

\subsection{Ethical Approval}

All procedures with the animals were approved by the Biomedicine Ethics Committee of the Institute of Biomedical Problems of the Russian Academy of Sciences/Physiology section of the 
Russian Bioethics Committee (protocol no. 421, 14.04 .2016 and protocol no. 444, 28.03.2017). All experiments were performed in strict accordance with the guidelines and recommendations in the Guide for the Care and Use of Laboratory Animals of the National Institutes of Health. All efforts were made to minimize animal suffering and discomfort. Animals were housed in a temperature-controlled room on a 12:12-h light-dark cycle with food pellets and water provided ad libitum.

\subsection{Animals and Hindlimb Unloading}

Male 2.5 month old Wistar rats weighing $225 \pm 10 \mathrm{~g}$ were obtained from the certified Nursery for laboratory animals of the Institute of Bioorganic Chemistry of the Russian Academy of Sciences (town of Pushchino, Moscow region, Russian Federation). Mechanical unloading was simulated using a standard hindlimb unloading (HU) model [32], following the recommendations provided by the European Convention for the protection of Vertebrate Animals used for Experimental and Scientific purposes (Council of Europe number 123, Strasbourg, 1985). In all experiments, prior to all surgical procedures, animals were anaesthetized with an intraperitoneal injection of tribromoethanol (240 $\mathrm{mg} / \mathrm{kg}^{-1}$ ). The depth of anesthesia was evaluated by testing the pedal withdrawal reflex (toe and foot pad pinch). After muscle excision, the rats were euthanized by a tribromoethanol overdose (I.P.) followed by cervical dislocation.

\subsubsection{Experiment 1}

Twenty-eight male Wistar rats weighing $225 \pm 10 \mathrm{~g}$ were randomly assigned to the following 4 groups ( $n=7$ /group): vivarium cage control (C), hindlimb unloading for 1 day (1HS), 3 days (3HS) and 7 days (7HS). Following HS, an isolated soleus muscle from the right hindlimb was placed in an organ culture medium and subjected to a bout of EC. An isolated soleus muscle from the left hindlimb was also placed in an organ culture medium but was not subjected to EC (resting muscle).

\subsubsection{Experiment 2}

Twenty-eight male Wistar rats weighing $225 \pm 10 \mathrm{~g}$ were randomly assigned to the following 4 groups ( $n=7$ /group): 1 ) vivarium cage control (C), 2) control rats an isolated soleus of which was incubated with $20 \mu \mathrm{M} \mathrm{GdCl}_{3}$ (Santa Cruz Biotechnology, Santa Cruz, CA, USA, cat \# sc-224004), SAC inhibitor $\left(\mathrm{C}+\mathrm{Gd}^{3+}\right)$, 3) hindlimb unloading for 7 days (HS), 4) hindlimb unloaded rats an isolated soleus, of which was incubated with $20 \mu \mathrm{M} \mathrm{GdCl}_{3}$, SAC inhibitor $\left(\mathrm{HS}+\mathrm{Gd}^{3+}\right)$. Upon HS completion, isolated soleus muscles from the right hindlimb were subjected to EC, while isolated soleus muscles from the left hindlimb remained resting in chilled oxygenated Krebs-Henseleit buffer.

\subsection{Eccentric Contractions of the Isolated Rat Soleus Muscle}

Rat soleus muscles were isolated from the hindlimbs and mounted between a lever arm of a position feedback servomotor (Aurora Scientific, Ontario, Canada) and an immovable pin in an organ bath and maintained at $37{ }^{\circ} \mathrm{C}$ with a thermo-regulated water-jacket. The bath contained Krebs-Henseleit buffer (120mM NaCl, $4.8 \mathrm{mM} \mathrm{KCl}, 25 \mathrm{mM} \mathrm{NaHCO}_{3}, 2.5 \mathrm{mM} \mathrm{CaCl}_{2}, 1.2 \mathrm{mM} \mathrm{KH}_{2} \mathrm{PO}_{4}$, $2 \mathrm{mM} \mathrm{MgSO}_{4}, 5 \mathrm{mM}$ Hepes) supplemented with $25 \mathrm{mM}$ glucose and equilibrated with a $95 \% \mathrm{O}_{2}, 5 \%$ $\mathrm{CO}_{2}$ gas. For the experiment 2, $20 \mu \mathrm{M}[26,33]$ of $\mathrm{GdCl}_{3}$ was added to the medium. EC protocol was adopted from O'Neil et al. (2009) [34]. Muscles were plunged into Krebs-Henseleit buffer for $15 \mathrm{~min}$ before all contractions. Eccentric contractions were evoked by electrically field stimulating the soleus muscle with a $80 \mathrm{~V} 50 \mathrm{~Hz}$ pulse for $3 \mathrm{~s}$ with a $1 \mathrm{~ms}$ square wave. $\mathrm{L}_{0}$ was measured during muscle dissection and evaluated with single twitch contractions followed by length adjustment. Left muscle was resting at $\mathrm{L}_{0}$ while right soleus was subjected to EC-contractions. The stimulation produced about $80 \%$ of the muscle's isometric maximum contraction, determined from preliminary experiments. At the onset of this electrical stimulus, the soleus muscle was lengthened $15 \%$ using a $100 \mathrm{~ms}$ ramp and then held at this length for the remainder of the contraction. At the end of the contraction, the soleus muscle was returned to optimal length using a $100 \mathrm{~ms}$ ramp. Each contraction was followed by 
a $10 \mathrm{~s}$ rest period during which time the muscle was maintained at $\mathrm{L}_{0}$. After the sixth repetition of contractions, there was an additional $50 \mathrm{~s}$ of rest period. This pattern of stimulation was repeated for a total of 10 sets of six repetitions, resulting in 60 contractions over a 22 min period. $\mathrm{L}_{0}$ was constantly checked during all sets of contractions in order to avoid possible knot slippage. Upon completion of the bout of eccentric contractions, the muscles were maintained at $\mathrm{L}_{0}$ for an additional $30 \mathrm{~min}$ [34] and then collected for biochemical analysis. Signals from the force transducer/dynamometer and electrical stimulator were controlled and monitored with DMC/DMA software (Aurora Scientific, Toronto, Ontario, Canada). Maximal eccentric contraction force $\left(\mathrm{P}_{0}\right)$ was measured and normalized to muscle cross-sectional area (CSA). CSA was evaluated as muscle wet weight divided by the product of muscle optimal length and density $\left(1.07 \mathrm{~g} \mathrm{~cm}^{-3}\right)$ [35,36]. Representative force and muscle length tracing from one typical eccentric contraction is shown in (Figure 7).

(a)

1400
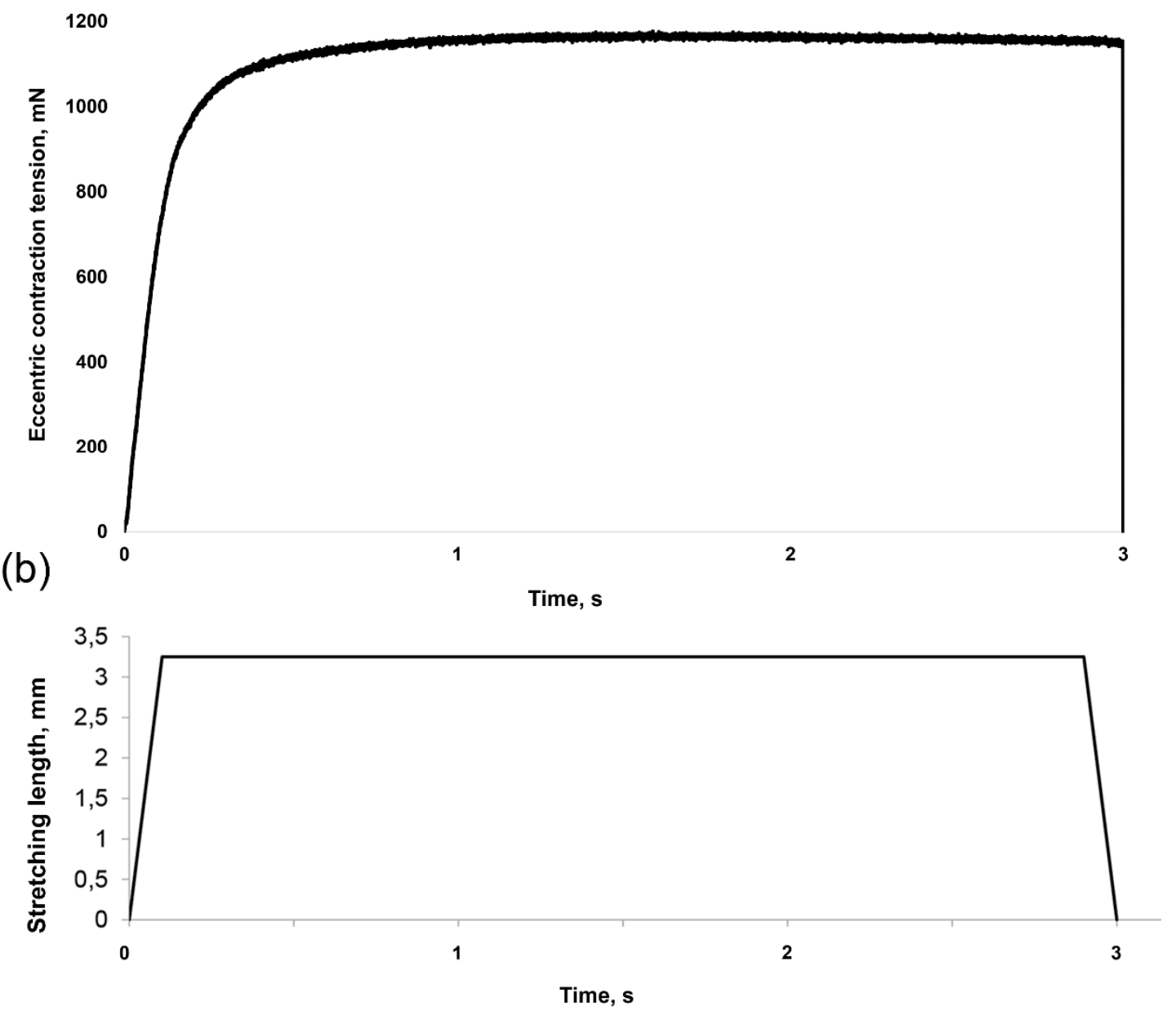

Figure 7. Representative force and muscle length tracing from one typical eccentric contraction. (a): changing in muscle force. (b): changing in muscle length.

\subsection{SUnSET Technique for Measuring the Rate of PS}

SUnSET (surface sensing of translation) is a nonradioactive technique that allows to measure protein synthesis in skeletal muscle. This technique involves the use of the antibiotic puromycin (a structural analogue of tyrosyl-tRNA), and anti-puromycin antibodies to detect the amount of puromycin incorporation into nascent peptide chains. It was shown that when puromycin is used at low concentrations $(40 \mathrm{nmol} / \mathrm{g})$, the accumulation of puromycin-conjugated peptides accurately 
reflects the rate of protein synthesis [37]. The SUnSET technique uses standard Western blotting and immunohistochemical technologies to visualize and quantify the rates of protein synthesis [38]. For measurements of protein synthesis, rats were given an intraperitoneal injection of $0.04 \mu \mathrm{mol} / \mathrm{g}$ puromycin hydrochloride (Enzo Life Sciences, Farmingdale, NY, USA) dissolved in PBS. Rat soleus muscles were extracted at exactly $15 \mathrm{~min}$ after I.P. puromycin injection.

\subsection{Western Blot Analysis}

The skeletal muscle tissue (30 mg) was homogenized in the ice-cold lysis buffer: $50 \mathrm{mM}$ Tris ( $\mathrm{pH}$ 7.4), $150 \mathrm{mM} \mathrm{NaCl}, 1 \%$ Nonidet P-40, $0.5 \%$ sodium deoxycholate, $0.1 \%$ SDS, $0.004 \%$ sodium azide, and $5 \mathrm{mM}$ EDTA, supplemented with $1 \mathrm{mM}$ DTT, $1 \mathrm{mM}$ PMSF, $10 \mu \mathrm{g} / \mathrm{mL}$ leupeptin, $5 \mu \mathrm{L} / \mathrm{mL}$ pepstatin and $1 \%$ aprotinin (Sigma-Aldrich, St. Louis, MO, USA), mammalian protease inhibitor cocktail (Amresco, Solon, OH, USA), and phosphatase inhibitor cocktail B (Santa Cruz Biotechnology, Santa Cruz, CA, USA). The muscle lysates were incubated for $20 \mathrm{~min}$ at $4{ }^{\circ} \mathrm{C}$ and then centrifugated for $10 \mathrm{~min}$ at $12000 \mathrm{~g}$. Protein concentration was quantified using Bradford protein assay (Bradford, 1976). Bovine serum albumin was used as a standard. The samples were diluted in Laemmli buffer. The total protein $(20-50 \mu \mathrm{g})$ was subjected to SDS-PAGE [39], and the proteins were then transferred to nitrocellulose membrane (Bio-Rad Laboratories, Hercules, CA, USA). Then, to verify equal loading of protein in all lanes, the nitrocellulose membrane was dyed by Ponceau $\mathrm{S}$. The membranes were blocked for $1 \mathrm{~h}$ at room temperature with the blocking buffer $(4 \%$ nonfat milk powder; TBS, $\mathrm{pH}$ 7.4; and $0.1 \%$ Tween 20) and incubated overnight at $4{ }^{\circ} \mathrm{C}$ with primary antibodies (diluted in TBS-T) against p-p70S6K (Thr 389) (1:2000; Santa Cruz Biotechnology, Santa Cruz, USA, sc-11759) and p70s6k (1:1000, Cell Signaling Technology, Beverly, MA, USA, \#9202), p-4E-BP1 (Thr37/46) (1:1000, Cell Signaling Technology, Beverly, MA, USA, \#2855,) and 4E-BP-1 (1:1000, Cell Signaling Technology, Beverly, MA, USA, \#9452), p-p90RSK1 (T359+S363) (1:1000, Abcam, Cambridge, MA, USA, ab32413) and p90RSK-1 (1:1000, Santa-Cruz Biotechnology, Beverly, MA, USA, sc-231), p-GSK-3ß (Ser 9) (1:1000, Cell Signaling Technology, Beverly, MA, USA, \#9322) and GSK-3 $\beta$ (1:1000, Cell Signaling Technology, Beverly, MA, USA, \#12456), P-S6RP (S240/244) (1:1000, Cell Signaling Technology, Beverly, MA, USA, \#5364), S6RP (1:1000, Cell Signaling Technology, Beverly, MA, USA, \#2217), puromycin (1:3000, Kerafast Inc., Boston, USA, EQ0001), GAPDH (1:10000, Applied Biological Materials Inc., Richmond, British Columbia, Canada, no. G041). Three 10-min washes with TBS-T were then performed. After that, the membranes were incubated for $1 \mathrm{~h}$ at room temperature with horseradish peroxidase-conjugated secondary antibodies to rabbit immunoglobulins (1:30000, Santa Cruz Biotechnology, Santa Cruz, CA, USA, sc-2004). For detection of puromycin-labeled proteins secondary goat anti-mouse IgG (H + L)-HRP conjugate antibodies (1:35000; Bio-Rad Laboratories, Hercules, CA, USA, \#1706516) were used. The membranes were then washed again in TBS-T 3 times for 10 min and incubated in Immun-Star HRP Chemiluminescent system (Bio-Rad Laboratories, Hercules, CA, USA, \#1706516). The protein bands were quantified using C-DiGit Blot Scanner (LI-COR Biotechnology, Lincoln, NE, USA) and Image Studio Digits software. Following image capture of phosphorylated proteins, membranes were stripped of the phosphospecific antibodies, using RestoreTM Western Blot Stripping Buffer (Thermo Scientific, Waltham, MA, USA), for $30 \mathrm{~min}$ at $37^{\circ} \mathrm{C}$ after which the membranes were re-probed with primary antibodies for each respective total protein. The signal from the phospho-protein was normalized to the total protein. For protein synthesis detection, the measurements of the chemiluminescent signals were performed by determining the density of each whole lane with the entire molecular weight range of puromycin-labeled peptides. Phospho and total blots were done on the same gel. Each gel contained samples from all groups. Protein samples were run at least in duplicate on the same gel. The representative blots are of the same samples (phospho and total). Total protein staining (Ponceau S) and GAPDH protein expression were used as loading controls. 


\subsection{Statistical Analysis}

All data are expressed as means \pm SEM. Two-sided t-tests were applied to determine differences between the resting and contracting muscle. Statistical analysis of the remaining data was performed using one-way ANOVA, two-way ANOVA (eccentric contractions · hindlimb unloading) or three-factorial ANOVA (eccentric contractions · hindlimb unloading · gadolinium injection) as indicated in the appropriate figure legends. Tukey's post hoc analysis was used to determine differences when interactions existed. Differences with values of $p<0.05$ were considered to be statistically significant.

\section{Conclusions}

The results of the study suggest that (i) hindlimb unloading results in a blunted anabolic response of the isolated rat soleus to a bout of EC, and (ii) attenuation of mTORC1-signaling and PS in response to EC in the unloaded soleus muscle may be associated with functional inactivation of SAC.

Author Contributions: The authors contributed to the paper as follows: S.T., T.M. and B.S. designed the study; T.M., S.T. performed the experiments; T.M., S.T. and B.S. analysed and interpreted the data, and wrote the manuscript. All authors have approved the final version of the manuscript and agree to be accountable for all aspects of the work. All persons designated as authors qualify for authorship, and all those who qualify for authorship are listed.

Funding: The work was supported by the Russian Foundation for Basic Research grant No. 16-34-60055.

Acknowledgments: The authors warmly thank Irina Petrova for excellent technical assistance during conduction of the experiments.

Conflicts of Interest: The authors declare no conflict of interest.

\section{Abbreviations}

$\begin{array}{ll}\text { 4E-BP1 } & \text { Eukaryotic translation initiation factor 4E-binding protein 1 } \\ \text { CSA } & \text { Cross-sectional area } \\ \text { DGK- } \zeta & \text { Diacylglycerol Kinase } \zeta \\ \text { EC } & \text { Eccentric contractions } \\ \text { eIF2B } & \text { Eukaryotic initiation factor 2B } \\ \text { ERK1/2 } & \text { Extracellular signal-regulated kinase 1/2 } \\ \text { GSK-3 } \beta & \text { Glycogen synthase kinase 3 } \beta \\ \text { HU } & \text { Hindlimb unloading } \\ \text { L }_{0} & \text { Optimal muscle length } \\ \text { mTORC1 } & \text { Mammalian target of rapamycin complex 1 } \\ \mathrm{P}_{0} & \text { Maximal muscle contraction tetanic force } \\ \text { p70S6K } & \text { Ribosomal protein S6 kinase p70 } \\ \text { PS } & \text { Protein synthesis } \\ \text { RPS6 } & \text { S6 ribosomal protein } \\ \text { SAC } & \text { Stretch-activated ion channels } \\ \text { SUnSET } & \text { Surface sensing of translation }\end{array}$

\section{References}

1. Goldberg, A.L.; Etlinger, J.D.; Goldspink, D.F.; Jablecki, C. Mechanism of work-induced hypertrophy of skeletal muscle. Med. Sci. Sports 1975, 7, 185-198. [PubMed]

2. Bodine, S.C.; Stitt, T.N.; Gonzalez, M.; Kline, W.O.; Stover, G.L.; Bauerlein, R.; Zlotchenko, E.; Scrimgeour, A.; Lawrence, J.C.; Glass, D.J.; et al. Akt/mTOR pathway is a crucial regulator of skeletal muscle hypertrophy and can prevent muscle atrophy in vivo. Nat. Cell Biol. 2001, 3, 1014-1019. [CrossRef] [PubMed]

3. Drummond, M.J.; Fry, C.S.; Glynn, E.L.; Dreyer, H.C.; Dhanani, S.; Timmerman, K.L.; Volpi, E.; Rasmussen, B.B. Rapamycin administration in humans blocks the contraction-induced increase in skeletal muscle protein synthesis. J. Physiol. 2009, 587, 1535-1546. [CrossRef] [PubMed] 
4. Hornberger, T.A.; Stuppard, R.; Conley, K.E.; Fedele, M.J.; Fiorotto, M.L.; Chin, E.R.; Esser, K.A. Mechanical stimuli regulate rapamycin-sensitive signalling by a phosphoinositide 3-kinase-, protein kinase B- and growth factor-independent mechanism. Biochem. J. 2004, 380, 795-804. [CrossRef] [PubMed]

5. Kubica, N.; Bolster, D.R.; Farrell, P.A.; Kimball, S.R.; Jefferson, L.S. Resistance exercise increases muscle protein synthesis and translation of eukaryotic initiation factor 2Bepsilon mRNA in a mammalian target of rapamycin-dependent manner. J. Biol. Chem. 2005, 280, 7570-7580. [CrossRef] [PubMed]

6. Roux, P.P.; Topisirovic, I. Regulation of mRNA translation by signaling pathways. Cold Spring Harb. Perspect. Biol. 2012, 4. [CrossRef] [PubMed]

7. Glass, D.J. Signalling pathways that mediate skeletal muscle hypertrophy and atrophy. Nat. Cell Biol. 2003, 5, 87-90. [CrossRef] [PubMed]

8. Franco, A., Jr.; Lansman, J.B. Stretch-sensitive channels in developing muscle cells from a mouse cell line. J. Physiol. 1990, 427, 361-380. [CrossRef] [PubMed]

9. Yeung, E.W.; Allen, D.G. Stretch-activated channels in stretch-induced muscle damage: Role in muscular dystrophy. Clin. Exp. Pharmacol. Physiol. 2004, 31, 551-556. [CrossRef] [PubMed]

10. Allen, D.G.; Whitehead, N.P.; Yeung, E.W. Mechanisms of stretch-induced muscle damage in normal and dystrophic muscle: Role of ionic changes. J. Physiol. 2005, 567, 723-735. [CrossRef] [PubMed]

11. Ato, S.; Makanae, Y.; Kido, K.; Fujita, S. Contraction mode itself does not determine the level of mTORC1 activity in rat skeletal muscle. Physiol. Rep. 2016, 4. [CrossRef] [PubMed]

12. Henriksen, E.J.; Tischler, M.E. Glucose uptake in rat soleus: Effect of acute unloading and subsequent reloading. J. Appl. Physiol. 1988, 64, 1428-1432. [CrossRef] [PubMed]

13. Lysenko, E.A.; Turtikova, O.V.; Kachaeva, E.V.; Ushakov, I.B.; Shenkman, B.S. Time course of ribosomal kinase activity during hindlimb unloading. Doklady Biochem. Biophys. 2010, 434, 223-226. [CrossRef] [PubMed]

14. Mirzoev, T.; Tyganov, S.; Vilchinskaya, N.; Lomonosova, Y.; Shenkman, B. Key Markers of mTORC1-Dependent and mTORC1-Independent Signaling Pathways Regulating Protein Synthesis in Rat Soleus Muscle During Early Stages of Hindlimb Unloading. Cell. Physiol. Biochem. Int. J. Exp. Cell. Physiol. Biochem. Pharmacol. 2016, 39, 1011-1020. [CrossRef] [PubMed]

15. Dupont, E.; Cieniewski-Bernard, C.; Bastide, B.; Stevens, L. Electrostimulation during hindlimb unloading modulates PI3K-AKT downstream targets without preventing soleus atrophy and restores slow phenotype through ERK. Am. J. Physiology. Regul. Integr. Comp. Physiol. 2011, 300, 408-417. [CrossRef] [PubMed]

16. Fluckey, J.D.; Dupont-Versteegden, E.E.; Knox, M.; Gaddy, D.; Tesch, P.A.; Peterson, C.A. Insulin facilitation of muscle protein synthesis following resistance exercise in hindlimb-suspended rats is independent of a rapamycin-sensitive pathway. Am. J. Physiol. Endocrinol. Metab. 2004, 287, E1070-E1075. [CrossRef] [PubMed]

17. Gwag, T.; Lee, K.; Ju, H.; Shin, H.; Lee, J.W.; Choi, I. Stress and signaling responses of rat skeletal muscle to brief endurance exercise during hindlimb unloading: A catch-up process for atrophied muscle. Cell. Physiol. Biochem. Int. J. Exp. Cell. Physiol. Biochem. Pharmacol. 2009, 24, 537-546. [CrossRef] [PubMed]

18. Loughna, P.; Goldspink, G.; Goldspink, D.F. Effect of inactivity and passive stretch on protein turnover in phasic and postural rat muscles. J. Appl. Physiol. 1986, 61, 173-179. [CrossRef] [PubMed]

19. Ingber, D.E. Cellular mechanotransduction: Putting all the pieces together again. FASEB J. Off. Publ. Fed. Am. Soc. Exp. Biol. 2006, 20, 811-827. [CrossRef] [PubMed]

20. Mirzoev, T.M.; Biriukov, N.S.; Veselova, O.M.; Larina, I.M.; Shenkman, B.S.; Ogneva, I.V. Parameters of fibers cell respiration and desmin content in rat soleus muscle at early stages of gravitational unloading. Biofizika 2012, 57, 509-514. [CrossRef] [PubMed]

21. Mirzoev, T.M.; Shenkman, B.S.; Ushakov, I.B.; Ogneva, I.V. Desmin and alpha-actinin-2 content in rat soleus muscle in the dynamics of gravitational unloading and subsequent reloading. Doklady Biochem. Biophys. 2012, 444, 144-146. [CrossRef] [PubMed]

22. You, J.S.; Dooley, M.S.; Kim, C.R.; Kim, E.J.; Xu, W.; Goodman, C.A.; Hornberger, T.A. A DGKzeta-FoxO-ubiquitin proteolytic axis controls fiber size during skeletal muscle remodeling. Sci. Signal. 2018, 11. [CrossRef]

23. McBride, T.A. Stretch-activated ion channels and c-fos expression remain active after repeated eccentric bouts. J. Appl. Physiol. 2003, 94, 2296-2302. [CrossRef] [PubMed]

24. McBride, T.A.; Stockert, B.W.; Gorin, F.A.; Carlsen, R.C. Stretch-activated ion channels contribute to membrane depolarization after eccentric contractions. J. Appl. Physiol. 2000, 88, 91-101. [CrossRef] [PubMed] 
25. Spangenburg, E.E.; McBride, T.A. Inhibition of stretch-activated channels during eccentric muscle contraction attenuates p70S6K activation. J. Appl. Physiol. 2006, 100, 129-135. [CrossRef] [PubMed]

26. Sonobe, T.; Inagaki, T.; Poole, D.C.; Kano, Y. Intracellular calcium accumulation following eccentric contractions in rat skeletal muscle in vivo: Role of stretch-activated channels. Am. J. Physiol. Regul. Integr. Comp. Physiol. 2008, 294, R1329-R1337. [CrossRef] [PubMed]

27. Ducret, T.; Vandebrouck, C.; Cao, M.L.; Lebacq, J.; Gailly, P. Functional role of store-operated and stretch-activated channels in murine adult skeletal muscle fibres. J. Physiol. 2006, 575, 913-924. [CrossRef] [PubMed]

28. Gulati, P.; Gaspers, L.D.; Dann, S.G.; Joaquin, M.; Nobukuni, T.; Natt, F.; Kozma, S.C.; Thomas, A.P.; Thomas, G. Amino acids activate mTOR complex 1 via Ca2+/CaM signaling to hVps34. Cell Metab. 2008, 7, 456-465. [CrossRef] [PubMed]

29. Zanou, N.; Schakman, O.; Louis, P.; Ruegg, U.T.; Dietrich, A.; Birnbaumer, L.; Gailly, P. Trpc1 ion channel modulates phosphatidylinositol 3-kinase/Akt pathway during myoblast differentiation and muscle regeneration. J. Biol. Chem. 2012, 287, 14524-14534. [CrossRef] [PubMed]

30. Ito, N.; Ruegg, U.T.; Kudo, A.; Miyagoe-Suzuki, Y.; Takeda, S. Activation of calcium signaling through Trpv1 by $\mathrm{nNOS}$ and peroxynitrite as a key trigger of skeletal muscle hypertrophy. Nat. Med. 2013, 19, 101-106. [CrossRef] [PubMed]

31. Hannan, K.M.; Thomas, G.; Pearson, R.B. Activation of S6K1 (p70 ribosomal protein S6 kinase 1) requires an initial calcium-dependent priming event involving formation of a high-molecular-mass signalling complex. Biochem. J. 2003, 370, 469-477. [CrossRef] [PubMed]

32. Morey-Holton, E.R.; Globus, R.K. Hindlimb unloading rodent model: Technical aspects. J. Appl. Physiol. 2002, 92, 1367-1377. [CrossRef] [PubMed]

33. Yeung, E.W.; Head, S.I.; Allen, D.G. Gadolinium reduces short-term stretch-induced muscle damage in isolated mdx mouse muscle fibres. J. Physiol. 2003, 552, 449-458. [CrossRef] [PubMed]

34. O'Neil, T.K.; Duffy, L.R.; Frey, J.W.; Hornberger, T.A. The role of phosphoinositide 3-kinase and phosphatidic acid in the regulation of mammalian target of rapamycin following eccentric contractions. J. Physiol. 2009, 587, 3691-3701. [CrossRef] [PubMed]

35. El-Khoury, R.; Bradford, A.; O'Halloran, K.D. Chronic hypobaric hypoxia increases isolated rat fast-twitch and slow-twitch limb muscle force and fatigue. Physiol. Res. 2012, 61, 195-201. [PubMed]

36. Gollnick, P.D.; Timson, B.F.; Moore, R.L.; Riedy, M. Muscular enlargement and number of fibers in skeletal muscles of rats. J. Appl. Physiol. Respir. Environ. Exerc. Physiol. 1981, 50, 936-943. [CrossRef] [PubMed]

37. Goodman, C.A.; Mabrey, D.M.; Frey, J.W.; Miu, M.H.; Schmidt, E.K.; Pierre, P.; Hornberger, T.A. Novel insights into the regulation of skeletal muscle protein synthesis as revealed by a new nonradioactive in vivo technique. FASEB J. Off. Publ. Fed. Am. Soc. Exp. Biol. 2011, 25, 1028-1039. [CrossRef] [PubMed]

38. Schmidt, E.K.; Clavarino, G.; Ceppi, M.; Pierre, P. SUnSET, a nonradioactive method to monitor protein synthesis. Nat. Methods 2009, 6, 275-277. [CrossRef] [PubMed]

39. Laemmli, U.K. Cleavage of structural proteins during the assembly of the head of bacteriophage T4. Nature 1970, 227, 680-685. [CrossRef] [PubMed]

(C) 2019 by the authors. Licensee MDPI, Basel, Switzerland. This article is an open access article distributed under the terms and conditions of the Creative Commons Attribution (CC BY) license (http://creativecommons.org/licenses/by/4.0/). 